\title{
The health impacts of khat: a qualitative study among Somali-Australians
}

\section{Heather Douglas LLB, LLM, PhD, Associate Professor \\ Merali Boyle \\ LLB(Hons), BS Researcher \\ Nicholas Lintzeris MB BS, PhD, FAChAM Director, ${ }^{2}$ and Clinical Associate Professor ${ }^{3}$ \\ 1 TC Beirne School of Law, University of Queensland, Brisbane, QLD. \\ 2 Drug and Alcohol Services, South East Sydney Local Health District, \\ Sydney, NSW. \\ 3 Faculty of Medicine University of Sydney, Sydney, NSW. \\ h.douglas@ law.uq.edu.au}

MJA 2011; 195: 666-669 doi: 10.5694/mjall.10166
"K hat" refers to the leaves of the Catha edulis tree, which is native to regions in East Africa and the Middle East. ${ }^{1}$ Khat has been chewed for centuries by people in countries such as Yemen, Ethiopia, Somalia and Kenya for its stimulant properties. $^{2}$ Khat usage in Australia has increased as more people from the Horn of Africa, particularly Somalia, have settled here. ${ }^{2}$

Khat has varying legal status across Australia. ${ }^{3}$ In Victoria, New South Wales and Tasmania it is possible to obtain a federal government license to import up to $5 \mathrm{~kg}$ of khat per month for personal use. In other states of Australia, the possession, sale and cultivation of khat is illegal. The prevalence of khat usage does not appear to depend on the legal status of the drug. ${ }^{3}$

Khat contains the alkaloids cathinone, cathine and norephedrine, with cathinone being the principal psychoactive component. ${ }^{4}$ These compounds are absorbed through the oral mucosa and the small intestine, and plasma concentrations of each peak $2-3$ hours after use. Cathinone has an elimination half-life of $1.5 \pm 0.8$ hours, ${ }^{5}$ and undergoes hepatic metabolism to norephedrine, which is excreted and can be detected in urine for several days. ${ }^{6}$ Only a small proportion $(<3 \%)$ of cathinone is excreted in urine unchanged. ${ }^{6}$

These alkaloids are structurally related to amphetamine, and act on dopaminergic, noradrenergic and serotonergic neurotransmitter systems to produce a range of physical and psychiatric effects that are qualitatively similar to the effects of other psychostimulants. ${ }^{7}$ Known and possible adverse health effects attributed to using khat are summarised in the Box.

There is conflicting evidence regarding the extent to which some health problems (eg, anxiety, depresAbstract
Objectives: To identify patterns of khat use among Somali-Australians in
Australia and to explore their views about the links between khat use and personal health.

Design, setting and participants: Qualitative study using semistructured focus groups among adult members of Somali communities in Brisbane, Sydney, Melbourne and Perth who volunteered to attend focus groups in January and December 2010.

Main outcome measures: Emergent themes related to Somali-Australians' understanding of the links between khat use and personal health.

Results: Nineteen focus groups included 114 participants. Khat use was reported to be common among the Somali community, and more common among men than women. Khat was usually chewed in prolonged sessions, producing mild psychostimulant effects such as increased energy, enhanced mood, reduced appetite and reduced sleep. Khat was widely perceived to be a food, not a drug, and as harmless, or even beneficial, to the user's health. Many users reported discontinuation effects such as lethargy, sleep disturbances and mood problems after sessions of heavy khat use, and some reported selfmedicating with alcohol to cope with such problems. Problems of addiction to khat were identified by some participants, but not all believed it is addictive. Many khat users reported visiting their health professionals for treatment of adverse effects and failing to disclose their khat use.

Conclusions: Health professionals require greater awareness of khat use and related health problems. Health promotion activities targeting communities with high levels of khat use are required to increase understanding of the potential risks of regular khat use, to promote harm-reduction strategies, and to increase awareness of services available for those experiencing harm. Health professionals should consider targeted screening for khat use among individuals from Horn of Africa communities who present to health services.

sion, diabetes, cardiovascular disease) are due to regular khat use as opposed to social health determinants, such as the social isolation, poverty, poor nutrition and high rates of smoking among displaced migrant communities. $^{2,19}$

In this article, we report qualitative data on Somali-Australians' views about patterns of khat use and their perceptions of its health effects.

\section{Methods}

Between January and December 2010, we obtained data from 19 focus groups comprising Somali-Australians.

Focus groups were conducted in Brisbane, Sydney, Melbourne and Perth in locations selected by representatives of Somali cultural groups (the "gatekeepers"). Gatekeepers asked community members to participate in the focus groups and advised them that the researchers wanted to talk about the law relating to khat and the effects of khat. Focus group participants were paid $\$ 20$ each to participate.

The semistructured focus groups lasted up to 90 minutes. Interpreters were used. The groups were led by one of us (MB) and a paid research assistant. Using open-ended questions based on a literature review, the facilitators asked participants about patterns of khat use, including how the drug is used and the social context of use, and about the effects of khat on health, including whether participants believed that khat was addictive or contributed to mental health issues or other physical health problems. Facilitators also introduced set 
themes, giving an opportunity to all participants to address the themes and discuss issues. Issues identified in early focus groups were raised by the facilitators in subsequent groups.

The focus groups were recorded and transcribed. We used an inductive mode of analysis to identify recurrent themes, and concepts were grouped using thematic content analysis. ${ }^{20}$

The ethics committee of the University of Queensland approved the study. An interpreter provided information about the study and consent form before individuals were asked to sign. Data were de-identified before analysis.

\section{Results}

We conducted 19 focus groups with 114 participants (79 men and 35 women). Participants were aged between 18 and 78 years and included both married and single people, people who used khat and people who did not. Most participants were born in Somalia, and the length of time since they arrived in Australia ranged from less than 1 year to 24 years.

\section{Who uses khat?}

Participants' estimates of the prevalence of khat use among the Somali community varied. Some estimated that khat use was as high as $80 \%$ among men and women. It was generally agreed that Somali men used khat more commonly than women. Although it is not possible for people under the age of 18 to obtain an import license for khat, some participants stated that teenagers sometimes used khat.

\section{How is khat used?}

Participants reported that khat was used in social settings, in the home, in restaurants or in khat cafes ("mafrishi"), and that usually men and women chewed separately. Khat leaves were chewed dried or fresh or, less commonly, made into a tea. Fresh leaves were preferred by users as they are easier to chew. People reported sitting and chewing for periods of 4-6 hours and up to 12 hours, and commonly drank sweet drinks while chewing, to counter the bitter taste of khat. People who used khat reported increased cigarette smoking during khat chewing.

Participants reported varying amounts and frequencies of khat use. Daily use, especially by men, was not uncommon: "If I can get it every day I will" (Somali man, Sydney). Most khat users claimed to use it 1-4 days per week. About $50 \mathrm{~g}$ of dried khat was chewed in a session. Estimates of the amount of fresh khat used in a session varied. A bundle of fresh khat ("madouf") weighs about 250 g. Participants reported that some users may eat one bundle in 24 hours, while others may eat two or three bundles. Participants estimated the cost of khat to be around $\$ 30$ for a bag of dried khat and $\$ 50$ for a bundle of fresh khat, although many reported that khat was shared freely.

\section{General effects and impact on general health}

When people do khat they become very hyper, their eyes come out and they want to be cleaning, they just want to be doing something inside the house. The blood pressure goes high; they sweat a lot. They get that energy and they want to do a lot of work. (Somali woman, Sydney.)

Many khat users reported feeling happier and more alert and having greater energy levels when they used khat. Many denied that khat had any negative physical side effects: "There's not any health risks that khat brings because in the whole [of] Africa people eat khat and no one has been ill because of khat" (Somali woman, Brisbane); and, "Most of those people been eating for like 20 years, and there's no effects whatsoever" (Somali man, Brisbane). Many participants said khat is not a drug, but more like a food, and therefore not harmful: "It's just like we eat as a salad" (Somali woman, Brisbane).

A number of users believed khat to be medically beneficial, rather than being associated with adverse health effects.

\section{Addiction}

Participants held a variety of views on whether khat was addictive. Some, predominantly users, reported that they did not believe khat is addictive,
Known and possible adverse effects of khat use

\begin{tabular}{|c|c|c|}
\hline $\begin{array}{l}\text { Central nervous } \\
\text { system }\end{array}$ & - & $\begin{array}{l}\text { Dizziness, impaired concentration, } \\
\text { insomnia, headaches, mydriasis, } \\
\text { conjunctival congestion } \\
\text { Impaired motor coordination, fine tremor } \\
\text { Agitation, labile affect, fatigue and } \\
\text { disrupted sleep often occur after } \\
\text { cessation of use } \\
\text { Transient psychosis is uncommon and } \\
\text { generally associated with heavy daily use } \\
\text { or other risk factors } \\
8,9\end{array}$ \\
\hline Dependence & 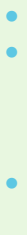 & $\begin{array}{l}\text { Misuse potential appears to be low } \\
\text { Discontinuation features (mild } \\
\text { withdrawal, including agitation, labile } \\
\text { affect, fatigue and disrupted sleep) are } \\
\text { common after regular use } \\
\text { Dependence has been reported, usually } \\
\text { associated with daily khat use }\end{array}$ \\
\hline $\begin{array}{l}\text { Cardiovascular } \\
\text { system }\end{array}$ & 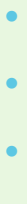 & $\begin{array}{l}\text { Tachycardia, arrhythmias, palpitations, } \\
\text { hypertension, vasoconstriction } \\
\text { Ischaemia, infarction, pulmonary oedema, } \\
\text { cerebral haemorrhage (all uncommon) }{ }^{11} \\
\text { Exacerbation of pre-existing cardiac } \\
\text { conditions }\end{array}$ \\
\hline $\begin{array}{l}\text { Respiratory } \\
\text { system }\end{array}$ & $\bullet$ & Tachypnoea, dyspnoea \\
\hline $\begin{array}{l}\text { Gastrointestinal } \\
\text { system }\end{array}$ & & $\begin{array}{l}\text { Dry mouth, polydipsia, periodontal } \\
\text { disease and dental caries }{ }^{12,13} \\
\text { Chronic gastritis, gastric ulcer }{ }^{14} \\
\text { Constipation, paralytic ileus } \\
\text { Reduced appetite, weight loss } \\
\text { Increased risk of upper gastrointestinal } \\
\text { malignancy } \\
\text { Liver disease (acute toxic effects in high }_{\text {doses) }}^{15}\end{array}$ \\
\hline $\begin{array}{l}\text { Reproductive } \\
\text { and obstetric } \\
\text { effects }\end{array}$ & & $\begin{array}{l}\text { Spermatorrhoea, impotence, altered } \\
\text { libido }^{16} \\
\text { Low birthweight, stillbirth, impaired } \\
\text { lactation }^{17}\end{array}$ \\
\hline $\begin{array}{l}\text { Metabolic and } \\
\text { endocrine } \\
\text { effects }\end{array}$ & & $\begin{array}{l}\text { Hyperthermia, perspiration, } \\
\text { hyperglycaemia }^{18}\end{array}$ \\
\hline
\end{tabular}

and that they could limit their khat use to once or twice a week. Others reported it to be addictive and that some people have difficulty controlling khat use.

\begin{abstract}
It's very hard for one to control his addiction to khat. One cannot easily say only sit for khat on Sunday or on Saturday. Whenever you get a chance, you want to grab it, because one is really addicted to it. (Somali man, Perth.)
\end{abstract}

Few identified a specific withdrawal syndrome upon stopping khat use, although a range of discontinuation effects were reported - most commonly, that extended episodes of heavy use were usually followed by a "crash", with disrupted sleeping patterns (usually prolonged sleep) and 
vivid bad dreams, lethargy, low mood, and anxiety and irritability for 1 or more days. Alternating periods of regular heavy use and discontinuation were said by some to have an impact on the user's psychosocial function, work performance and relationships. Some participants stated that they used alcohol to relieve the insomnia and restlessness they experienced after a khat chewing session and were concerned that this practice of combining khat and alcohol contributed to mental health problems. Others reported that khat users sometimes sought medical treatment for sleep and mood problems.

The sad part is they go to their

[general practitioner] here and the GP gives them happy pills. Because they can't sleep so they get antidepressants and then their mental issue gets worse. It's very sad ... and they never tell the doctor this is what happened. (Somali woman, Sydney.)

\section{Psychoactive and mental health effects}

The increased energy level and enhanced mood from khat use led some users to suggest that khat is a useful treatment for depression: "We use it for remedy and it doesn't cost the government" (Somali woman, Melbourne). Conversely, commonly identified psychological health problems such as disrupted sleep patterns, low mood and irritability were reported to occur after the effects of khat had worn off.

A minority of participants identified a link between heavy khat use and more severe mental health problems:

It's a very major source of madness, of craziness. People are alright if they stop it, they can come back alright ... but when you overuse it, and overuse it, that's when you come to this situation. (Somali man, Perth.)

The general view of participants was that people do not become more violent upon using khat, although some participants reported domestic violence linked to khat use. Many participants suggested that such conflict arises out of disagreements about the amount of time and money spent on khat, rather than as a direct effect of the drug:
Some people when they eat the khat they come to you very angry. The first thing they do is hitting the kids and the mother and all those things. (Somali woman, Sydney.)

The husband will become abusive in defending his actions [khat chewing]. The partner is not happy with that, the children are not getting a fair share of his life, all those kinds of things, then it may constitute domestic violence because of defending his habit. (Somali man, Sydney.)

\section{Physical health effects}

Many participants reported that khat users experienced dental problems "I see a lot of dental issues ... You have people, very young people, their teeth are falling out" (Somali woman, Sydney). Some participants reported that khat users often neglected dental hygiene after a long night of chewing. "They eat a lot of sugar cubes or sometimes they use lollies, tea, something to make it sweet because it's very bitter" (Somali man, Sydney). Most reported that khat chewing caused constipation, although some reported a laxative effect.

Many claimed they used khat as a treatment for diabetes mellitus. Khat was said to "help with blood sugar level" (Somali man, Brisbane).

Many associated khat use with increased libido and fertility: "It's more like Viagra" (Somali man, Melbourne), and "It increases the amount of his sperm" (Somali man, Sydney).

\section{Discussion}

Our qualitative study identified that khat is commonly used by members of the Australian Somali community, particularly men, and that participants' views about the links between khat use and personal health varied regarding its benefits and harms. Use is linked to community networks and cultural traditions, and may also be associated with existing high levels of mental health disorders (anxiety, depression and post-traumatic stress disorder) among displaced refugee communities. $^{21}$

Large quantities of khat need to be consumed in order to achieve a "high". The fresh leaves preferred by khat users contain a higher ratio of cathinone to the less psychoactive cathine, $^{22}$ and are usually sourced from local trees. Dried khat is usually imported into Australia from Kenya or Ethiopia. ${ }^{23}$ The effects that were seen as positive (increased energy, elevated mood, reduced appetite) and the adverse effects (sleep and mood disorders, poor appetite, constipation) commonly reported by participants were consistent with the weak psychostimulant properties of the active components of khat. Some participants also identified a negative impact on psychosocial functioning and relationships, although more severe druginduced psychosis or violence were reported to be uncommon. Participants suggested that when it occurs it is not a direct effect of the drug; we suggest that such behaviour may be due to the effects (or discontinuation effects) of khat.

The concurrent consumption of large volumes of sugary drinks and sweets to counteract the bitter taste of khat, coupled with reduced appetite and poor nutrition, is likely to contribute to poor oral health.

Overwhelmingly, participants in this study incorrectly believed that khat was harmless or possibly beneficial for a range of medical complaints. There were a number of instances where perceived effects contradicted the evidence - for example, reports that khat was useful in treating diabetes. Such reports may arise from the appetite suppressant effects of khat, yet are in contrast to the limited evidence suggesting that khat may increase blood glucose levels in people with type 2 diabetes. ${ }^{18}$ The concurrent consumption of sweet food and drink may also contribute to the development of diabetes. Further, the belief that khat use increases libido and fertility contradicts the limited evidence that long-term use of khat may reduce sperm count, volume and motility. ${ }^{16}$

Difficulties in detecting and responding to health problems associated with khat use may be compounded by poor health literacy and poor utilisation of health services by people who use khat, different cultural understandings of the role of khat as a drug, stigma regarding disclosure of khat use to health care 
providers, and low awareness among health practitioners of khat use, its effects, and the health issues affecting refugees. $^{24}$

Those experiencing adverse effects are most likely to access general health services complaining of specific symptoms (eg, sleep or mood problems, constipation) and may not report their khat use because of concerns regarding stigma, illegality or genuine belief that khat use is not linked to any health problems. Khat users may also present (or be referred) to drug and alcohol treatment services with dependence issues, although there are no specific services available for khat users in Australia. Multicultural drug and alcohol health services are available in some states and may be able to offer more culturally specific assistance to patients.

Health professionals have a role to play in educating users about potential harms arising from khat use, promoting responsible use of the drug in order to minimise the negative health effects for the individual and for the community, and informing community members who experience problems about the services available to them. Health information resources regarding khat use are available through websites, such as the Australian Drug Foundation's DrugInfo site (http://www.druginfo.adf.org.au/). Importantly, many users reported not disclosing their khat use to health professionals, and we therefore rec- ommend that health professionals should routinely enquire about khat use and related health problems with patients of Somalian or other East African background, incorporated into enquiries regarding lifestyle factors such as use of tobacco, alcohol and other substances.

Acknowledgements: This research was supported by a grant from the National Drug Law Enforcement Research Fund. The National Drug Law Enforcement Research Fund is funded by the Australian Government Department of Health and Ageing.

Competing interests: No relevant disclosures.

Received 17 Feb 2011, accepted 6 Oct 2011.

1 Al-Hebshi N, Skaug N. Khat (Catha edulis) - an updated review. Addict Biol 2005; 10: 299-307.

2 Fitzgerald J, Lawrence L. Khat: a literature review. Melbourne: Centre for Culture, Ethnicity and Health, 2009. http://www.ceh.org.au/about/ projects/pages/khat_review.aspx (accessed Nov 2011).

3 Douglas H, Pedder M. Legal regulation of the drug khat in Australia. J Law Med 2010; 18: 284-301.

4 Manghi R, Broers B, Khan R, et al. Khat use: lifestyle or addiction? J Psychoactive Drugs 2009; 41: 1-10.

5 Toennes SW, Harder S, Schramm M, et al. Pharmacokinetics of cathinone, cathine and norephedrine after the chewing of khat leaves. Br J Clin Pharmacol 2003; 56: 125-130.

6 Cox G, Rampes H. Adverse effects of khat: a review. Adv Psychiatr Treat 2003; 9: 456-463.

7 Graziani M, Milella MS, Nencini P. Khat chewing from the pharmacological point of view: an update. Subst Use Misuse 2008; 43: 762-783.

8 Stefan J, Mathew B. Khat chewing: an emerging drug of concern in Australia? Aust NZ J Psychiatry 2005; 39: 842-843.

9 Bhui K, Warfa N. Trauma, khat and common psychotic symptoms among Somali immigrants: a quantitative study. J Ethnopharmacol 2010;132: 549-553.

10 Kassim S, Islam S, Croucher R. Validity and reliability of a Severity of Dependence Scale for khat (SDS-khat). J Ethnopharmacol 2010; 132: 570-577.

11 Al-Motarreb A, Al-Habori M, Broadley KJ. Khat chewing, cardiovascular diseases and other internal medical problems: the current situation and directions for future research.

JEthnopharmacol 2010; 132: 540-548.

12 Ali AA, Al-Sharabi AK, Aguirre JM, Nahas R. A study of 342 oral keratotic white lesions induced by qat chewing among 2500 Yemeni. J Oral Pathol Med 2004; 33: 368-372.

13 Mengel R, Eigenbrodt M, Schunemann T, Flores de Jacoby L. Periodontal status of a subject sample of Yemen. J Clin Periodontol 1996; 23: 437-443.

14 Raja'a YA, Noman TA, Al-Warafi AK, et al. Khat chewing is a risk factor of duodenal ulcer. Saudi Med J 2000; 21: 887-888.

15 Chapman MH, Kajihara M, Borges G, et al. Severe, acute liver injury and khat leaves. NEngl J Med 2010; 362: 1642-1644.

16 El-Shoura SM, Abdel Aziz M, Ali ME, et al. Deleterious effects of khat addiction on semen parameters and sperm ultrastructure. Hum Reprod 1995; 10: 2295-2300.

17 Mwenda JM, Arimi MM, Kyama MC, Langat DK. Effects of khat (Catha edulis) consumption on reproductive functions: a review. East Afr Med J 2003; 80: 318-323.

18 Saif A, Al-Qirbi R, Al-Geiry A, et al. Effect of Catha edulis on plasma glucose and C-peptide in both type 2 diabetics and non-diabetics. J Ethnopharmacol 2003; 86: 45-49.

19 Armstrong EG. Research note. Crime, chemicals and culture: on the complexity of khat. J Drug Issues 2008; 38: 631-648.

20 Braun V, Clarke V. Using thematic analysis in psychology. Qual Res Psychol 2008; 3: 77-101.

21 Tiong ACD, Patel MS, Gardiner J, et al. Health issues in newly arrived African refugees attending general practice clinics in Melbourne. Med J Aust 2006; 185: 602-606.

22 Chappell J, Lee M. Cathinone preservation in khat evidence via drying. Forensic Sci Int 2010; 195: 108-120.

23 Sykes W, Coleman N, Desai P, et al. Perceptions of the social harms associated with khat use. Research Report 44. London: Home Office, 2010. http://www.homeoffice.gov.uk/publications/ science-research-statistics/research-statistics/ crime-research/horr44/ (accessed Nov 2011).

24 Murray S, Skull S. Hurdles to health: immigrant and refugee health care in Australia. Aust Health Rev 2005; 29: 25-29. 